Available online at GSC Online Press Directory

GSC Biological and Pharmaceutical Sciences

e-ISSN: 2581-3250, CODEN (USA): GBPSC2

Journal homepage: https://www.gsconlinepress.com/journals/gscbps

(RESEARCH ARTICLE)

\title{
Descriptive epidemiology of uterine cervix cancer at the medical oncology unit of the Yaoundé general hospital-Cameroon
}

\author{
Nguendo Yongsi H. Blaise ${ }^{1,2,{ }^{*}}$ and Tchinda Fossi Cedric ${ }^{2}$ \\ ${ }^{1}$ Institute for Training and Demographic Research (IFORD), University of Yaoundé II, Cameroon. \\ ${ }^{2}$ Department of Public Health, School of Health Sciences, Catholic University of Central Africa, Cameroon.
}

Publication history: Received on 02 October 2019; revised on 22 October 2019; accepted on 24 October 2019

Article DOI: https://doi.org/10.30574/gscbps.2019.9.1.0189

\begin{abstract}
Uterine cervix cancer is the most common cancer found worldwide, mostly in developing countries. In Africa as well as in the Caribbean, it represents the second cause of mortality, just after maternal mortality. In Cameroon, data on cervix cancer are erratic, whereas the incidence of the disease is increasing. This paper is designed to define the epidemiological features of uterine cervix cancer, since it could help identifying behavioral, environmental and genetic risks factors involved in its development. A 4-year retrospective study of patients seen with the diagnosis of cervix cancer at the Medical Oncology unit of the Yaoundé General Hospital between January 2012 and December 2015. Then a prospective study was conducted among health professionals working in the same oncological unit in 2017. The demographic pattern (age of patients, socio professional activity, marital status), clinical features (cancer diagnosis), treatment modalities and outcome were studied. Of the 7775 patients enrolled in the study, $3.61 \%(\mathrm{n}=281)$ were carriers of uterine cervix cancer. We noted a relatively large annual growth of cases and the annual average was 27 cases. The average age of our patients was 55.46 years with extreme ages ranging from 23 to 88 years Carcinoma of the cervix occurs much more frequently among women of lower income and education level. Although several risk factors were suspected in our study such as age, sexual factors (including STIs), none of them really testify their responsibility in the genesis of the cancer. However, improving the effective management of different patients suffering from cervix cancer requires an improvement in the conditions for the early and voluntary detection of people at risk, and the quality of care administered to patients.
\end{abstract}

Keywords: Epidemiology; Risks factors; Uterine cervix cancer; Yaoundé General Hospital; Cameroon

\section{Introduction}

Cancer is a tumor associated with both anarchic and indefinite proliferation of a cell clone leading to destruction of the original tissue, local, regional and general tumor extension and death of the individual [1]. It is one of the leading causes of death in adults, with one in ten deaths attributable to cancer worldwide [2]. Often considered as a disease of developed countries, cancer is nowadays a public health problem in developing countries. In 2015, global statistics showed that 21.9 million people have suffered and 6.2 million deaths have been attributed to the disease [3]. Forecasts for 2020 indicate a frequency of cancers that could increase by 50\%, with 15 million new cases per year and an annual case-fatality of 10 millions [4]. This increase in the number of cancer cases is mainly due to the aging of the population, the importance of smoking and the growing adoption of health-damaging lifestyles. According to WHO, cancer will be the third leading cause of death in Africa in 2020. In this region (Africa), nearly 25\% of malignant tumors are associated with infections, including the hepatitis B virus (liver cancer), Human Papillomavirus (cervical cancer) and Helicobacter pylori (stomach cancer), HIV / AIDS (associated with non-Hodgkin's malignant lymphoma, Kaposi's sarcoma) [5]. It is believed that in the coming decades, cancer will be a major cause of morbidity and mortality that will take precedence

\footnotetext{
${ }^{*}$ Corresponding author

E-mail address: sir_nguendoyongsi@hotmail.com
} 
over infectious and parasitic diseases. With regard to uterine cervix cancer, it is the most common cause of cancer death among women (522,000 deaths in 2012) and the most commonly diagnosed cancer among women worldwide [6]. It is responsible for nearly 200,000 annual deaths, of which more than three-quarters are in developing countries [7]. Uterine cervix cancer has the particularity of affecting young woman, making it the cancer responsible for the decrease in life expectancy in the third world [8]. According to Globocan (2012), uterine cervix cancer was the most common form of cancer in women with $23.8 \%$ compared to other forms of cancer, namely: breast cancer (21.3\%), liver cancer (4.7\%) and Kaposi's sarcoma (3.8\%) [9]. In Cameroon, according to the study conducted by Enow et al. [10], Uterine cervix cancer was the second most common type of cancer with $13.8 \%$ after breast cancer (18.5\%). Traditional risk factors such as age, the existence of a family history of cervical cancer, and race, especially the African-born population [11], are nowadays associated with other risk factors such as diet, long life expectancy, urbanization, lifestyle and especially genetic factors and factors related to environment (occupational exposures) [12]. In short, high incidence of uterine cervix cancer can be explained by the combination of genetic and environmental factors. Delay in the diagnosis is often the rule, thus spending out any possibility of curative treatment. Management of the disease at the metastatic stage still remains a clinical challenge in terms of survival, and improvement of patients' quality of life. Many low- and middle-income countries facing the double burden of uterine cervix cancer and breast cancer need to implement costeffective and affordable combination interventions to tackle those diseases that can be easily prevented [13]. Therefore, it seemed useful to take stock of the current state of the pathology is useful, describing the epidemiological situation in Yaoundé.

\section{Patients and methods}

This is a 4-year retrospective study of patients seen with the diagnosis of cancer of prostate at the Medical Oncology Unit of the Yaoundé General Hospital, which is a reference hospital where the largest proportion of cancers in the city and even the entire central Africa region, is diagnosed. The study focused on the medical records of patients received in consultation from January 2012 to December 2015. The entry criterion included any patient managed in the Medical Oncology Service with a complete medical record (histologically proven cervical cancer and exploitable record). The diagnostic protocol consisted of vaginal and rectal markings on the ultrasound gel shadowed by the following sequences: Sagittal T1 SE, T2 SE in the 03 planes, T1 FAT SAT sagittal then T1 FAT SAT with gadolinium injection in the 03 planes. The average duration of the exam was 60 minutes. All exams were performed on an AIRIS ELITE (Hitachi Medical System) open magnet low magnetic field (0.3T) device.

From the hospital records, we identified patients' files and retained only diagnosis of malignant uterine cervix tumor. Using a standardized form, the following information data were systematically collected: socio-demographic characteristics, clinical information (tumor location), and histological diagnosis. Data collected were first recorded using Excel software. Then, data recorded were coded according to the International Classification of Diseases-Oncology (CIMO or ICD-0) for histological diagnosis and ICD 10th edition (ICD 10th) for tumor localization [14-15]. Data monitoring was carried out using the Epi info software version 6.00, while data analyzes were performed through SPSS 18.1 software.

\section{Results}

\subsection{Epidemiological characteristics}

Of the 7775 patients registered in the Medical Oncology Unit, 281 patients had uterine cervix cancer during the period under review. It is the commonest cervical tumor accounting for a prevalence of 3.61\%. However, the annual prevalence varies over the years within the Medical Oncology Unit. This prevalence follows a growing pattern from 2012 to 2015 where the highest value was obtained (4.65\%) (Figure 1). 


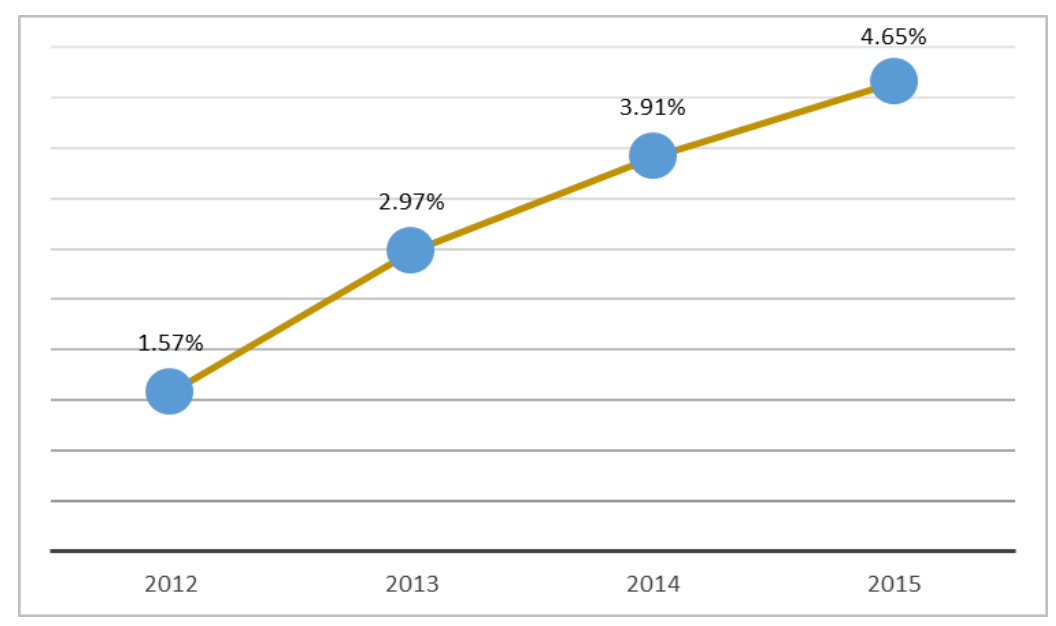

Figure 1 Annual Prevalence of Cervical Cancer at the Medical Oncology Unit.

We noticed that there is a gradual increase in the prevalence during the study period, with a rising profile from 2012 to 2015 with a highest value of $54.80 \%$ registered in 2015 (Figure 2).

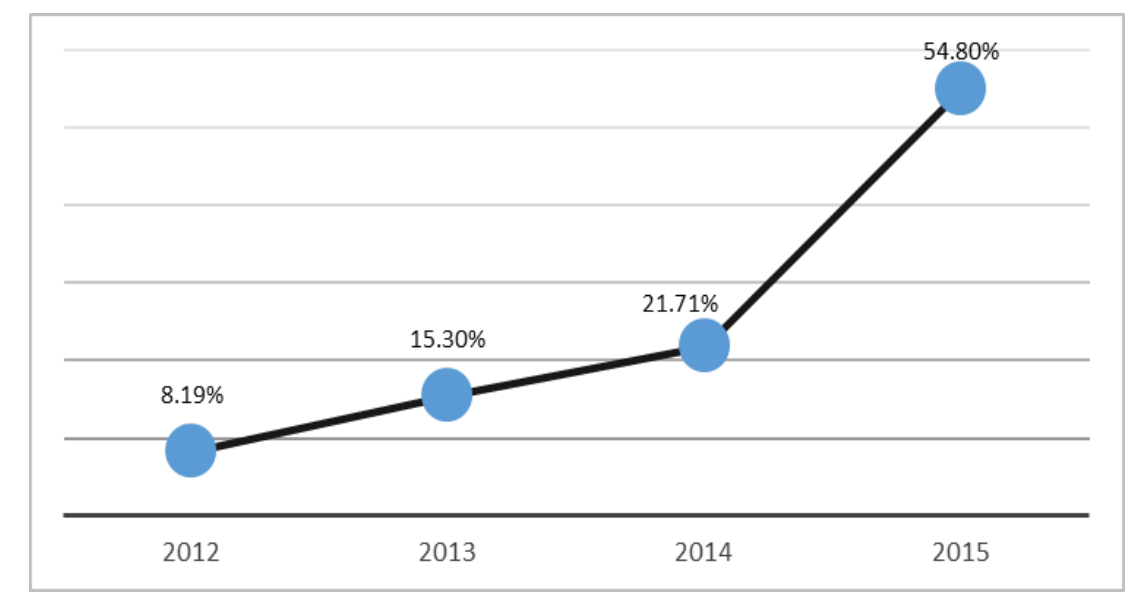

Figure 2 Distribution of cervical cancer cases by year of consultation.

Screening practice for cervical cancer is not common among all Medical Oncology Unit caregivers. In fact and according to table 1 , only $54.54 \%$ carry out systematic screening. Overall, the most common type of screening is cervical vaginal smear $(90.90 \%)$.

Table 1 Practice of cervical cancer screening by SOMHGY caregivers $(n=22)$

\begin{tabular}{lll}
\hline Practice of cervical cancer screening & & \\
\hline Use of systematic screening & 12 & $54,54 \%$ \\
Occasional screening & 10 & $45,46 \%$ \\
Screening method used & & \\
Cervical vaginal smear & 20 & $90,90 \%$ \\
Biopsy of the cervix & 2 & $09,09 \%$ \\
Frequency of cervical smear screening & & \\
Once a year & 6 & $27,27 \%$ \\
Every 2 years & 7 & $31,81 \%$ \\
Irregular & 9 & $40,92 \%$ \\
\hline
\end{tabular}




\subsection{Sociodemographic characteristics of patients}

Patients over 40 years of age represented the majority of women diagnosed with cervical cancer (65.84\%). Women of Christian denomination accounted for $76.15 \%$. With regard to marital status, table 2 shows that most were married $(63.70 \%)$, and the dominant level of education was secondary $(53.02 \%)$, followed by higher (37.38\%).

Table 2 Sociodemographic characteristics of patients with cervical cancer

\begin{tabular}{|c|c|c|}
\hline Characteristics & Effective & Percentage (\%) \\
\hline \multicolumn{3}{|l|}{ Age } \\
\hline 25 - 39 years & 96 & 34,16 \\
\hline 40 - 78 years & 185 & 65,84 \\
\hline Total & 281 & 100,00 \\
\hline \multicolumn{3}{|l|}{ Marital status } \\
\hline Married & 179 & 63,70 \\
\hline Single & 57 & 20,28 \\
\hline Widow / Divorced & 45 & 16,02 \\
\hline Total & 281 & 100,00 \\
\hline \multicolumn{3}{|l|}{ Level of education } \\
\hline Without / Primary & 27 & 09,60 \\
\hline Secondary & 149 & 53,02 \\
\hline University & 105 & 37,38 \\
\hline Total & 281 & 100,00 \\
\hline \multicolumn{3}{|l|}{$\begin{array}{l}\text { Socio-Professional } \\
\text { Category }\end{array}$} \\
\hline Teacher & 97 & 34,52 \\
\hline Nurse / Doctor & 59 & 21,00 \\
\hline $\begin{array}{l}\text { Military / Police / } \\
\text { Gendarme }\end{array}$ & 38 & 13,52 \\
\hline Lawyer & 30 & 10,67 \\
\hline $\begin{array}{l}\text { Shopkeeper / } \\
\text { Businesswoman }\end{array}$ & 24 & 08,54 \\
\hline Civil servant & 18 & 06,41 \\
\hline Without / Housewife & 15 & 05,34 \\
\hline Total & 281 & 100,00 \\
\hline \multicolumn{3}{|l|}{ Religion } \\
\hline Christian & 214 & 76,15 \\
\hline Muslim & 12 & 04,27 \\
\hline Adventist & 55 & 19,57 \\
\hline Total & 281 & 100,00 \\
\hline
\end{tabular}

\subsection{Healthcare professionals' knowledge about uterine cervix cancer and its screening}

Table 3 shows the distribution of health care staff based on their knowledge on cervical cancer. We notice that all healthcare professionals at the medical oncology Unit have already heard about cervical cancer. However, levels of knowledge vary from one health professional to another. Half of the staff state they have an "average" knowledge about the severity and curability of cancers. All of them were aware of the clinical manifestations of cancer, as well as of the existence of cancer screening. Pap smear was cited as the most commonly used screening tool for cervical cancer and only $09.1 \%$ mentioned the biopsy technique of the cervix. For most of those healthcare professionals, the main sources of information on cancer screening are respectively Internet (90.91\%) and seminars / forums (81.82\%). 
Table 3 Nursing staff knowledge of cervical cancer and its screening $(n=22)$

\begin{tabular}{lll}
\hline Variables & Effective & $\mathbf{\%}$ \\
\hline Source of information used for screening purposes & & \\
$\quad$ Internet & 20 & 90,91 \\
Medical dictionaries & 7 & 31,82 \\
$\quad$ Seminars / Forums & 18 & 81,82 \\
$\quad$ Specialized journals & 8 & 36,36 \\
$\quad$ TV / radio & 4 & 18,18 \\
$\quad$ Level of knowledge regarding cancer severity & 3 & \\
low & 11 & 13,64 \\
way & 8 & 50,00 \\
High & & 36,36 \\
Level of knowledge regarding the curability of cancer & 6 & \\
low & 10 & 27,27 \\
Way & 6 & 45,45 \\
High & 20 & 27,27 \\
Knowledge about the means or technique of cancer screening & \\
Cervical vaginal smear & 2 & 80,90 \\
Biopsy of the cervix & & 09,10 \\
\hline
\end{tabular}

Figure 3 below shows the distribution of healthcare professionals according to their status and according to their general knowledge of uterine cervix cancer (symptomatology, diagnosis, screening, risk factors).

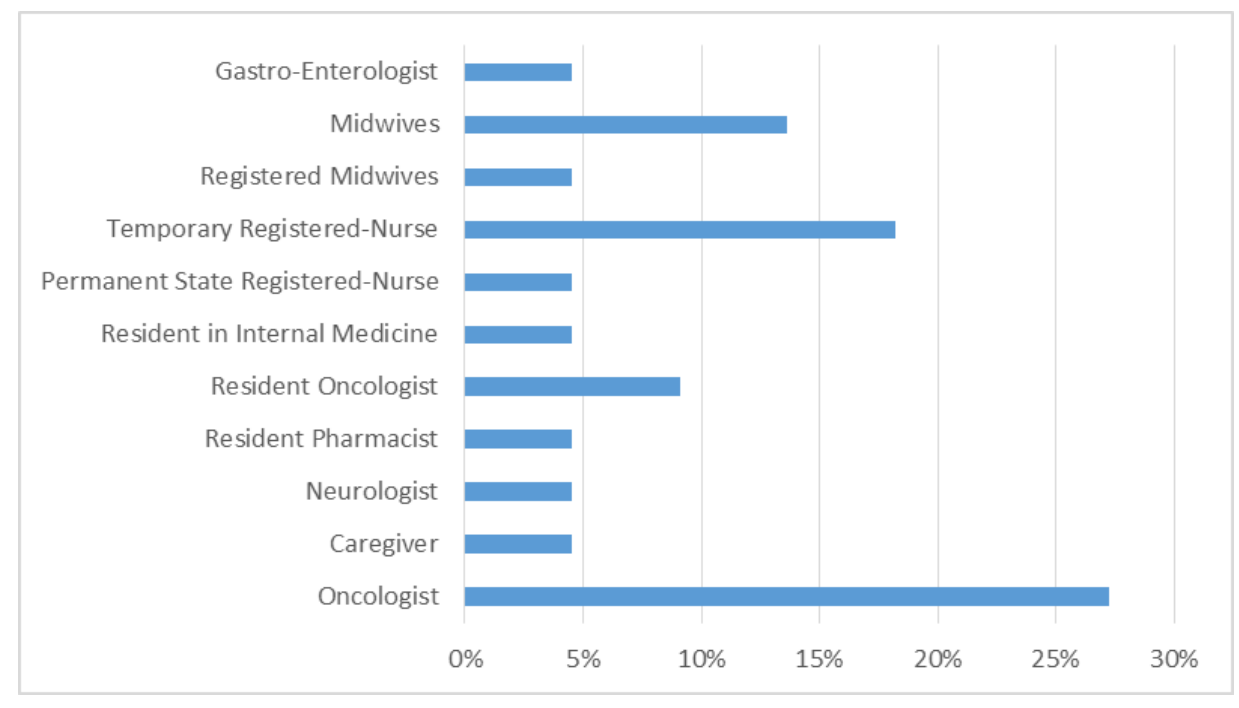

Figure 3 Distribution of healthcare professionals by status in the profession and according to their knowledge of uterine cervical cancer.

\subsection{Attitudes of healthcare professionals toward cervical cancer}

According to table 4, almost all caregivers are in favor of cervical cancer screening. Two-thirds of these caregivers are ready to inform patients and populations about cervical cancer and its screening. Of those recommending a screening method, 90.91\% would recommend Pap smear and only 9.09\% would recommend Cervical Biopsy. 
Table 4 Attitude of health care professionals regarding cancer screening

\begin{tabular}{lcc}
\hline & Effective (n) & $\mathbf{\%}$ \\
\hline For cervical cancer & 16 & 72,72 \\
Information of the population about cervical cancer & 20 & 90,90 \\
Population information on cervical cancer screening & 17 & 77,27 \\
Participation as a health professional at a cervical cancer screening & 15 & 68,18 \\
campaign & & \\
Suggested screening methods for women & 20 & 90,91 \\
Cervical vaginal smear & 2 & 09,09 \\
Biopsy of the cervix & & \\
\hline
\end{tabular}

\section{Discussion}

Uterine cervix cancer is an abnormal proliferation of cervical cells, due to excessive cellular proliferation, abnormal, anarchic and autonomous, destroying the cervix with local and remote invasion. In more than $95 \%$ of cases, uterine cervix cancer is due to the HPV virus (Human papillomavirus). Indeed, there are precursor lesions that evolve for 10 to 15 years before giving cancer. Several names have been devoted by the different classifications: dysplasias, intraepithelial neoplasia (CIN), pre-cancerous lesions of low and high grades [16]. Occurrence of cervical cancer could therefore be equated with a long period of neglect. At the Medical Oncology Unit, results show that prevalence rate over the 4 years of study was $3.61 \%$. This high prevalence rate reflects a major problem of this cancer within the female population of Cameroon. In fact, in urban areas in Cameroon, cervical cancer accounted for $13.8 \%$ of all cancers irrespective of sex [17]. This is in line with the position of other authors who have studied gynecological and breast cancers in the Cameroonian capital and who ranked it second after the breast cancer [18]. Developing countries such as Cameroon are very vulnerable to the occurrence of this cancer because of the known risk factors of premature intercourse (before the age of 17), multiple partners, active smoking ( $>15$ cigarettes per day) or passive and the longterm use of oral contraceptives ( $>5$ years), being the daughter of a woman who took diethylstilbestrol during pregnancy, the traveling profession of the husband, chronic cervico-vaginal infections, immune deficiency (HIV, renal transplantation), numerous pregnancies and especially oncogenic HPV infections are very common [19]. Combination of the two oncogenic viruses (HIV and HPV) is responsible for the amplification of carcinogenesis with the risk of early development of uterine cancer [20]. The prominence of epithelial tumors, particularly squamous cell carcinomas, is confirmed by other studies [21]. However, prevalence of cervical cancer varies by year and adopts a growing pattern. In our records, we found an annual average of 70.25 cases of cervical cancer. This result is comparable to that of Diabate et al. [22], but much higher than those of Touré et al. [23] and Bannour et al. [24]. Frequency of cervical cancer in our study has steadily increased over the years from 23 cases (8.19\%) in 2012 to 154 cases (54.80\%) in 2015. This reflects the trend observed in developing countries where incidence has been increasing for more than two decades [25-26]. The significant increase in the number of new cases is largely attributable not only to the increased use of detection or screening techniques and to the extension of the cervical smear during health, but also to the increase in the number of healthcare professionals. In addition, radio and television programs are organized by oncologists and obstetricians on both local and international channels, promoting a better knowledge of the disease, thus increasing the number of consultations. The most common risk factors for cervical cancer are Human Papilloma Virus, HIV / AIDS, smoking and pills (estrogen / progestogen contraception). The main risk factor that we noted in patient records was Human Papilloma Virus infection. Contamination occurs primarily during unprotected sex. The virus is transmitted by simple contact with the skin and mucous membranes and reaches about $80 \%$ of people who have sex. But it must be said that nearly two-thirds of women who have sex are in contact with the virus, but only 1 to $2 \%$ of them infected with the virus and will develop cervical cancer. As HPV is the main cause of cervical cancer, primary prevention would be immunization against different serotypes such as the HPV16 which is involved in 50\% cases [27]. However, many other factors (early and high frequency of sexual intercourse, varied partners, STIs, smoking, age etc.) have also been identified as contributing factors [28-29]. In our study, the average age of patients with cervical cancer is 55.46 years whereas the minimum age is 23 years, underlying the presence of young patients. This minimum age is comparable to that found by Bannour et al. [30]. These results show that development of cervical cancer generally occurs in young individuals and this could be justified by an early sexual life, either by STIs or by multiple partners. Therefore, early detection is the main way to fight this cancer because it improves chances of cancer survival. Developing countries do not always have means and material resources to adequately manage cervical cancer, and consequently screening is unorganized and survival is low [31]. In our study, $63.70 \%$ of patients were married women or widows. Patients' marital 
status is similar to that of the general population, with almost every woman living as a couple. Level of knowledge of cervical cancer along with screening methods by the healthcare professionals is good. This is similar to studies conducted by Bello et al. [32]. This result is also similar to that of Kemfang et al. [33] on the knowledge, attitudes and practices of Health Professionals on Breast Cancer at Yaoundé General Hospital, Cameroon. The fact that a significant proportion of the staff consider that cervical cancer screening can be done using cervical biopsy suggests a capacitybuilding of those healthcare professionals to biopsy technique, mostly those who are likely to receive patients during mass screening campaigns. All healthcare professionals in our study cited cervicovaginal smear as the primary means of screening, a proportion which is higher than that reported in Nigeria (73\%) by Odusanya et al. [34]. This difference could be explained by the fact that our study population includes not only nurses as in the study of Odusanya et al. (Op.cit), but also Oncologists, specialized doctors and Registered-nurses whose training is more thorough. The low rate of the practice of other screening methods, other than Pap smear, may be justified by a lack of personal commitment from the healthcare givers to search for information. As a result, those healthcare givers should be sensitized to the interest and modalities of screening practice using existing methods other than cervico-vaginal smear. Another method of screening to be suggested is the use of visual inspection, which has been successfully used in resource-limited countries such as Cote d'Ivoire (Horo et al.[35]. The present study revealed a low rate (9.09\%) of cervical biopsy practice among healthcare staff despite their good knowledge of cervical biopsy. This result shows that the good knowledge about screening methods does not always imply good screening practice. Reasons for this low practice rate of cervical biopsy screening are mainly the lack of a national cervical biopsy-screening program, the fear of effects and the high cost of biopsy screening.

\section{Conclusion}

Cancer of the cervix, pathology mainly of infectious origin, is the tenth cancer in women by its frequency and the fifteenth most deadly. Over the past 25 years, its incidence and mortality rates have been steadily declining, although the decline in the last five years has slowed down. This means that cervical cancer remains a public health problem in developing countries in general and Cameroon in particular. Reduction of morbidity and mortality related to cervical cancer requires measures such as early detection, appropriate treatment tailored to the stage of the cancer, addressing the contributing factors. Since cervical cancer is diagnosed late in developing countries where mass screeningprogramme is not systematic and where radiotherapy is not available, MRI is an alternative to better assess tumor growth. Public authorities are challenged to establish a systematic screening policy, and to provide medical oncology departments of national hospitals with appropriate technical facilities, including a radiotherapy unit. Currently, few African countries consider cancers to be a real public health priority because of the high pressure exerted by infectious diseases such as malaria, tuberculosis and HIV infection on public funds allocated to health. Further, due to limited resources and to a lack of knowledge and perspective with respect to current and future morbidity and mortality attributable to cancers, establishment of cancer registries by national health stakeholders should be considered as a priority. The expected aging of the African population associated with the development of new risk factors for cancer (sedentary lifestyle, changes in diet, changes in reproductive life) are arguments in support of a better documentation of cancers in Africa. However, better management of uterine cervix cancer patients involves improving the conditions for the early and voluntary detection of women at risk, as well as improving the quality of care provided to patients.

\section{Compliance with ethical standards}

\section{Acknowledgments}

The authors are grateful to the Medical Oncology Unit of the Yaoundé General Hospital in Cameroon for allowing access to patients' medical records.

\section{Disclosure of conflict of interest}

The authors state that there is no conflict of interest.

\section{Statement of ethical approval}

The present research work does not contain any studies performed on animals/humans subjects by any of the authors'.

\section{Statement of informed consent}

Informed consent was obtained from all individual participants included in the study. 


\section{References}

[1] Disaia PJ and Creasman WT. (1993). Pre invasive disease of the cervix. Clinical Gynaecologic Oncology, Mosby, 4, 1-36.

[2] Chidyaonga-Maseko F, Chirwa ML and Muula AS. (2015). Underutilization of cervical cancer prevention services in low and middle income countries: A review of contributing factors, The Pan African Medical Journal, 21.

[3] WHO/ICO Information Center of HPV and Cervical Cancer (HPV Information Center). Human Papillomavirus and Related Cancers in the World. Summary Report 2010.

[4] Poorolajal J and Jenabi E. (2016). The association between BMI and cervical cancer risk: A meta-analysis, European Journal of Cancer Prevention, 25(3), 232-238.

[5] Parkin DM, Pisani P and Munoz N. (1998). The global health burden of infection. In: Weiss, R.A., Beral, V., Newton R, editor(s). Infections and human cancer. Cold Spring Harbor Laboratory Press.

[6] Ferlay J, Soerjomataram I, Ervik M and GLOBOCAN. (2012). Cancer Incidence and Mortality Worldwide: IARC Cancer base, 1 (11).

[7] Forouzanfar MH, Foreman KJ and Delossantos AM. (2011). Breast and cervical cancer in 187 countries between 1980 and 2010 : a systematic analysis, Lancet, (11), 61351-61352.

[8] Curado MP, Edwards B, Shin HR, Storm H, Ferlay J, Heanue M, et al. (2007). Cancer incidence in five continents. IARC Scientific publications, Lyon, 9 (160), 23-41.

[9] Momenimovahed Z, Ghoncheh, M, Pakzad R, Hasanpour H and Salehiniya H. (2017). Incidence and mortality of uterine cancer and relationship with Human Development Index in the world, Cukurova Medical Journal, 42, 233240.

[10] Enow Orock GE, Ndom P and Doh AS. (2012). Current cancer incidence and trends in Yaounde, Cameroon. Oncol Gastroenterol Hepatol., 1(1), 58-63.

[11] Sankaranarayanan R, Basu P, Wesley RS, Mahe C, Keita N, Mbalawa CC, Sharma R, Dolo A, Shastri SS, Nacoulma M, Nayama M, Somanathan T, Lucas E, Muwonge R, Frappart L and Parkin DM. (2010). IARC Multicentre Study Group on Cervical Cancer Early Detection; Accuracy of visual screening for cervical neoplasia: Results from an IARC multicentre study in India and Africa. Int J Cancer. 110(6), 907-913.

[12] Bruni L, Diaz M, Castellsagué M, Ferrer E, Bosch FX and de Sanjosé S. (2010). Cervical human papillomavirus prevalence in 5 continents: Meta-analysis of 1 million women with normal cytological findings, The Journal of Infectious Diseases, 202(12), 1789-1799.

[13] Bello TO, Olugbenga-Bello AI, Oguntola AS, Adeoti ML and Ojemakinde OM. (2012). Knowledge and Practice of Breast Cancer Screening Among Female Nurses and Lay Women in Osogbo, Nigeria, West African Journal of Medicine, 30 (4), 296-300.

[14] WHO. (2010). Le cancer du col de l'utérus dans la région africaine de l'OMS : situation actuelle et perspectives, 6.

[15] Percy C, Van Holten V and Muir C. (1990). International Classification of Diseases for Oncology (ICD-0). 2nd ed. Geneva: WHO.

[16] Pierre A and Bernard-Alex G. (2015). Les cancers dans les pays en développement. Médecine tropicale, 1-7.

[17] Enow Orock GE, Ndom P and Doh AS. (2012). Current cancer incidence and trends in Yaounde, Cameroon. Oncol Gastroenterol Hepatol., 1(1), 58-63.

[18] Tebeu PM, Petignat P and Mhawech-Fauceglia P. (2009). Gynecological malignancies in Maroua, Cameroon, Int J Gynaecol Obstet, 104(2), 148-159.

[19] Makuza JD, Nsanzimana S, Muhimpundu MA, Pace LE, Ntaganira J and Riedel DJ. (2015). Prevalence and risk factors for cervical cancer and pre-cancerous lesions in Rwanda. The Pan African Medical Journal, 22, 35-45.

[20] Fitzmaurice C, Dicker D, Pain A, Hamavid H, Moradi-Lakeh M, MacIntyre MF and Wolfe C. (2015). The global burden of cancer. JAMA Oncology, 1(4), 505-527.

[21] Mariko Kadidiatou épouse keita. (2008). Aspects histopathologiques des cancers du col de l'utérus au Mali: à propos de 85 cas. Tthese de Doctorat en médecine, Université de Bamako, 79. 
[22] Diabate AS, Gui- Bile LN, Dede NS, Kouadio E, Kabas RM, Yapo P and Ouattara DN. (2015). IRM du cancer du col de l'utérus en milieu tropical, Journal African Imagery Médical, 1(7), 30-38.

[23] Touré M, Adoubi I, Didi-Kouko Coulibaly J, Toowlis A and Echimane KA. (2011). Aspects épidémiologiques, anatomo-cliniques et thérapeutiques du cancer du col utérin dans le service de cancérologie du CHU de Treichville à Abidjan, Médecine d'Afrique Noire, 58(10), 473-478.

[24] Bannour N, Boughizane S, Naifer R, Slama O, Trabelsi A, Bibi M, Zheni S, Ben Abdallah M., Khairi H and Bouaouina N. (2004). Le cancer invasif du col utérin dans le centre tunisien. Approches épidémiologique, clinique et thérapeutique. Étude rétrospective de 96 cas. Oncologie, 6, 481-488.

[25] Ries L, Melbert D, Krapcho M, Mariotto A, Miller BA, Feuer EJ et al. (2007). SEER Cancer Statistics Review, 19752004, National Cancer Institute. Bethesda.

[26] Durowade K, Osagbemi G, Salaudeen A, Musa O, Akande T, Babatunde 0 and Ibrahim O. (2012). Prevalence and risk factors of cervical cancer among women in an urban community of Kwara State, north central Nigeria, Journal of Preventive Medicine and Hygiene, 53, 12-22.

[27] Munoz N and Bosch FX. (1996).The causal link between HPV and cervical cancer and its implications for prevention of cervical cancer, Bull Pan Am Health Organ., 30 (4), 362-77.

[28] Horo A, Jaquet A, Ekouevi D, Toure B, Coffie P, Effi B, Messou E, Minga A, Moh R, Kone M, Dabis F and Sasco Annie J. (2012). Cervical cancer screening by visual inspection in Côte d'Ivoire, operational and clinical aspects according to HIV status, BMC Public Health, 12, 237.

[29] NPB. (2007).

[30] Bannour N, Boughizane S, Naifer R, Slama O, Trabelsi A, Bibi M, Zheni S, Ben Abdallah M., Khairi H and Bouaouina N. (2004). Le cancer invasif du col utérin dans le centre tunisien. Approches épidémiologique, clinique et thérapeutique. Étude rétrospective de 96 cas. Oncologie, 6, 481-488.

[31] Bouslah S, Soltani MS, Ben Salah A and Sriha A. (2014). Connaissances, attitudes et pratiques des femmes tunisiennes en matière de dépistage du cancer du sein et de celui du col de l’utérus, Psycho Oncologie, 8, 123.

[32] Bello TO, Olugbenga-Bello AI, Oguntola AS, Adeoti ML and Ojemakinde OM. (2012). Knowledge and Practice of Breast Cancer Screening Among Female Nurses and Lay Women in Osogbo, Nigeria, West African Journal of Medicine, 30 (4), 296-300.

[33] Kemfang DJ, Ngowa1 LF, Domgue FJ, Ngassam A, Noa CC, Tsuala FJ, Fongang E and Jean Marie Kasia MJ. (2015). Connaissances, attitudes et pratiques des professionnels de la santé sur le cancer du sein à Yaoundé, Health Sciences Diseases, 16(3), 1-6.

[34] Lurie N, Margolis KL, McGovern PG, Mink PJ and Slater JS. (1997). Why do patients of female physicians have higher rates of breast cancer and cervical cancer screening? Journal of General Internal Medecine, 12, 34-43.

[35] Crosbie EJ, Einstein MH, Franceschi S and Kitchener HC. (2013). Human papillomavirus and cervical cancer, Lancet, 382(9895), 889-899.

\section{How to cite this article}

Nguendo Yongsi HB and Tchinda FC. (2019). Descriptive epidemiology of uterine cervix cancer at the medical oncology unit of the Yaoundé general hospital-Cameroon. GSC Biological and Pharmaceutical Sciences, 9(1), 83-91. 